\title{
Overnight Supplemental Blue, Rather than Far-red, Light Improves Microgreen Yield and Appearance Quality without Compromising Nutritional Quality during Winter Greenhouse Production
}

\author{
Qinglu Ying, Yun Kong, and Youbin Zheng \\ School of Environmental Sciences, University of Guelph, 50 Stone Road East, \\ Guelph, ON N1G 2W1, Canada
}

Additional index words. Brassica juncea, carotenoids, chlorophylls, cotyledon, Eruca sativa, height, phenolics, stem, yield

\begin{abstract}
To determine whether supplemental blue light (B) or far-red light (FR) overnight can promote microgreen elongation to facilitate machine harvesting and improve microgreen quality and yield, two common microgreen species, mustard (Brassica juncea) and arugula (Eruca sativa), were grown in a greenhouse in Guelph, Ontario, Canada, during January 2019. Low-intensity $\left(14 \mu \mathrm{mol} \cdot \mathrm{m}^{-2} \cdot \mathrm{s}^{-1}\right) \mathrm{B}$ or FR was applied to microgreens overnight from $1730 \mathrm{HR}$ to $0630 \mathrm{HR}$, and no supplemental lighting (D) was used as a control. After 2 weeks of light treatments, B compared to D promoted stem elongation by $16 \%$ and $10 \%$, respectively, and increased crop yield by $32 \%$ and $\mathbf{2 9 \%}$, respectively, in mustard and arugula. $B$ compared to $D$ also increased the cotyledon area in mustard and leaf mass per area in arugula and enhanced cotyledon color in both species despite having no effects on total chlorophyll, carotenoid, and phenolic contents. However, FR did not increase stem length or fresh weight compared with $D$, reduced plant height compared with $B$ in both species, and reduced the cotyledon area in arugula. FR, compared with $D$ and $B$, reduced the stem diameter and phytochemical contents of both species. Therefore, low-intensity $B$ can be applied overnight for winter greenhouse microgreen production because of its beneficial effects on appearance quality and crop yield without negatively affecting nutritional quality.
\end{abstract}

Microgreens are tender leafy vegetables harvested after two cotyledons have fully developed, with or without the first true leaves, that are becoming popular in the worldwide markets due to their high nutritional value (Treadwell et al., 2016; Xiao et al., 2012). In some regions that have long and cold winters, like Canada, winter production of microgreens in local greenhouses has become an option. The profits of greenhouse production of fruits

Received for publication 29 May 2020. Accepted for publication 1 July 2020.

Published online 12 August 2020.

We thank Natural Sciences and Engineering Research Council of Canada and Greenbelt Microgreens Ltd. for their financial support. We thank Heliospectra AB (Gothenburg, Sweden) for providing LED lighting technologies for this study. Thanks to Dave Llewellyn for his excellent technical support and informative discussions during the trials. We also thank Gale Bozzo for his guidance regarding phytochemical analyses and Chase Jones-Baumgardt for her technical support during harvesting.

Y.Z. is the corresponding author. E-mail: yzheng@ uoguelph.ca.

This is an open access article distributed under the CC BY-NC-ND license (https://creativecommons. org/licenses/by-nc-nd/4.0/). and vegetables such as tomato and cucumber are decreasing due to the increased costs of greenhouse operation and intense price competition with imported produce. However, it is difficult to import or transport microgreens from other regions to Canada because they are highly perishable products (Mir et al., 2017). Moreover, microgreens have a short growth period (7-20 d), so they can be grown with many cropping cycles in greenhouses throughout the winter.

The low natural light level during winter months is one of the most limiting factors for greenhouse vegetable production in northern regions, such as Canada (Demers and Gosselin, 2002). During the winter months (NovemberJanuary), the natural daily light integral (DLI) in the northern United States and southern Canada normally ranges between 5 and 15 $\mathrm{mol} \cdot \mathrm{m}^{-2} \cdot \mathrm{d}^{-1}$, resulting in a daily average photosynthetic photon flux density (PPFD) of 58 to $174 \mu \mathrm{mol} \cdot \mathrm{m}^{-2} \cdot \mathrm{s}^{-1}$ (Faust and Logan, 2018). The available light level in greenhouses could be further reduced by $30 \%$ to $60 \%$ due to the transmission losses through greenhouse construction and covering materials (Critten, 1993; Llewellyn et al., 2013). Therefore, in these regions, the DLI in greenhouses can be as low as 2 to $6 \mathrm{~mol} \cdot \mathrm{m}^{-2} \cdot \mathrm{d}^{-1}$ during the winter months (daily average PPFD of 23-69 $\mu \mathrm{mol} \cdot \mathrm{m}^{-2} \cdot \mathrm{s}^{-1}$ depending on the greenhouse structure). For microgreens, the recommended minimum DLI has been elusive in the literature. However, for greenhouse vegetable (including microgreens) production in southern Canada, the yield and most quality metrics increased with the increasing DLI within the range of 6.9 to $24 \mathrm{~mol} \cdot \mathrm{m}^{-2} \cdot \mathrm{d}^{-1}$ (JonesBaumgardt et al., 2020; Kong et al., 2018a; Kong and Zheng, 2019). Consequently, winter greenhouse production under low natural light conditions is a great challenge for growers due to the decreased yield and quality of horticultural crops, including microgreens.

Supplemental lighting (SL) is a common practice for greenhouse production because it is a way to deal with low natural light issues. Hofstra et al. (1969) found that low-intensity supplemental light is efficient for carbon assimilation and plant growth, and $\approx 13 \mu \mathrm{mol} \cdot \mathrm{m}^{-2} \cdot \mathrm{s}^{-1}$ supplemental light is five-times more efficiently used during nighttime compared with daytime in terms of $\mathrm{CO}_{2}$ fixation. Overnight SL can be economically beneficial in some regions, such as Ontario in Canada, where the electricity cost during nighttime is almost half that during the daytime. Therefore, overnight SL may benefit crop production more efficiently. Lightemitting diodes (LEDs) have been increasingly used as a SL source in greenhouses because of the many advantages over traditional lamps (Brandon et al., 2012; Gómez et al., 2013). Among the advantages, the adjustable spectral quality enables growers to control plant growth and development using LED lights based on their production purposes. However, the optimal spectral quality of LED is unclear for overnight low-intensity SL during winter greenhouse microgreen production in terms of yield and quality.

Microgreens with longer stems are normally more attractive to most consumers; therefore, plant height is one of the most important microgreen appearance qualities. In addition, plant height or stem length is an important technological quality trait. Most microgreens are harvested with a minimum height of $5 \mathrm{~cm}$ (Kyriacou et al., 2016), and inhibition of stem elongation would delay harvest time, thereby extending the crop cycle time. Also, commercial microgreen production has been increasingly switching from handharvesting to machine-harvesting to reduce labor costs. Microgreens with plant height less than $5 \mathrm{~cm}$ are difficult to harvest with machines (Kong et al., 2019a). Although daytime SL can increase the microgreen yield and some quality traits, it inhibits stem elongation and causes difficulty with machine harvesting (JonesBaumgardt et al., 2019). Therefore, it would be interesting to investigate whether stem elongation can be promoted by overnight SL without compromising yield and quality during winter greenhouse production.

Recently, our laboratory found that monochromatic blue light (B, 400-500 nm) instead of red light (R, 600-700 nm) promoted stem elongation of indoor-grown microgreens under LED lighting as the sole light source with $P P F D$ of $\approx 100$ or $50 \mu \mathrm{mol} \cdot \mathrm{m}^{-2} \cdot \mathrm{s}^{-1}$ and 
photoperiods of both 24 and $16 \mathrm{~h}$ (Kong et al., 2019a, 2019b). In addition to promoting stem elongation, $\mathrm{B}$ compared to $\mathrm{R}$ also reduced cotyledon size, changed plant color, and increased biomass partitioning to the stem despite the similar fresh weight $(\mathrm{FW})$ of the stems and leaves (Kong et al., 2019a). We concluded that the promoted stem elongation is a shade-avoidance response mediated by $\mathrm{B}$ associated with low phytochrome activity, as indicated by the low phytochrome photostationary state (PPS; <0.6) (Kong et al., 2018b), which may also involve a co-action among the three photoreceptors (phytochrome, cryptochrome, and phototropin) (Kong and Zheng, 2020). However, it is unclear whether a similar promotion effect on stem elongation associated with other responses can be found with overnight supplemental B in winter greenhouse microgreen production.

In a natural light environment, the enriched far-red light (FR) level can also promote stem elongation as a shadeavoidance response by lowering the phytochrome equilibrium (i.e., decreasing the phytochrome activity) (Demotes-Mainard et al., 2016). An increased FR level at the end of day has been shown to enhance stem elongation in many species, including chrysanthemum (Chrysanthemum morifolium) (Lund et al., 2007), poinsettia (Euphorbia pulcherrima) (Islam et al., 2014), and tomato (Solanum lycopersicum) rootstock (Chia and Kubota, 2010). Extending the photoperiod with supplemental FR light is extremely useful to promote shoot elongation of Japanese pear (Pyrus pyrifolia) during the first several months of the seedling stages (Ito et al., 2014). However, plants grown under a light environment with high FR levels might undergo some negative effects, such as decreased chlorophyll content and leaf thickness (Demotes-Mainard et al., 2016). These negative effects may potentially compromise microgreen quality.

It is unknown whether B or FR is more effective as an overnight SL source for promoting elongation while having fewer negative effects on yield and other quality traits for winter greenhouse microgreen production. Therefore, the objective of this study was to evaluate the effects of overnight SL with lowintensity B or FR LED, using no SL as a control, on winter greenhouse production of arugula and mustard microgreens in terms of appearance quality (including stem elongation), crop yield, and phytochemical contents.

\section{Materials and Methods}

Greenhouse conditions and plant materials. The experiment was performed in the Edmund $\mathrm{C}$. Bovey building research greenhouse at the University of Guelph, Guelph, ON (lat. $43^{\circ} 33^{\prime} \mathrm{N}$, long. $80^{\circ}$ $15^{\prime} \mathrm{W}$ ) during January of 2019 . Three adjacent greenhouse compartments $(6.2 \mathrm{~m} \times$ $7.6 \mathrm{~m}$ ) with three benches oriented east to west were used in the experiment (Fig. 1A). Each compartment was independently controlled using an Argus environmental control system (Argus Controls Systems Ltd., Surrey, BC, Canada) at day/night temperatures and relative humidity $(\mathrm{RH})$ of $21 / 19{ }^{\circ} \mathrm{C}$ and $70 \%$, respectively. The temperature and $\mathrm{RH}$ were also logged using the same system with 15-min intervals in each compartment. The natural light intensity in the greenhouse was logged by a sunlight-calibrated quantum sensor (SQ-110; Apogee Instruments, Logan, UT) tethered to the datalogger (HOBO U12 Temp/RH/2 External Logger; Onset Computer Corp., Bourne, MA) and placed on the center bench in the middle compartment to measure natural PPFD data at the bench level in 5-min intervals throughout the trial. The daily variations in air temperature, $\mathrm{RH}$, natural $P P F D$, and DLI inside the experimental greenhouse are presented in Fig. 2.

Seeds of mustard (Brassica juncea; Johnny's Selected Seeds, Winslow, ME) and arugula (Eruca sativa; Suba Seeds Company S.P.A., Longiano, FC, Italy) microgreens were sown in fiber trays $(48.5 \mathrm{~cm} \times 23 \mathrm{~cm} \times 3.5 \mathrm{~cm})$ with pre-incorporated organic substrates from Greenbelt Microgreens Ltd. (Lynden, ON, Canada). The seeding rate was $36.4 \mathrm{~g} \cdot \mathrm{m}^{-2}$ for both arugula (1.56 mg/seed) and mustard $(1.63 \mathrm{mg} / \mathrm{seed})$. A thin layer of coconut coir was used to cover the substrates to maintain moisture. On the same day of seeding, two sown trays (one species each) were placed at the center of each greenhouse bench to start treatments. Plants were monitored daily and top-irrigated until drainage was observed.

Experimental design and treatment setup. For each species, a randomized complete block design ( 3 treatments $\times 3$ replicates) was used in the experiment (Fig. 1A). The three replicates (i.e., blocks) were allocated to the three greenhouse compartments. Each compartment had three benches. In each block (i.e., compartment), three treatments were randomly assigned to three benches: 1) D, no supplemental light (SL); 2) B, supplemental 14 $\mu \mathrm{mol} \cdot \mathrm{m}^{-2} \cdot \mathrm{s}^{-1} \mathrm{~B}$ LED light $(400-500 \mathrm{~nm}$, peak at $445 \mathrm{~nm}$ ); and 3) FR, supplemental 14 $\mu \mathrm{mol} \cdot \mathrm{m}^{-2} \cdot \mathrm{s}^{-1}$ far-red LED light $(700-800 \mathrm{~nm}$, peak at $735 \mathrm{~nm}$ ). The light spectral distributions under different SL light treatments are presented in Fig. 3. PPS values of nighttime light treatments were calculated based on the light spectral distribution using the protocol developed by our laboratory (Mah et al., 2019) according to Sager et al. (1988). For each bench, SL was provided by one programmable LED light fixture (LX601C; Heliospectra AB, Gothenburg, Sweden) mounted $1.35 \mathrm{~m}$ above the bench (measured from the bottom of the

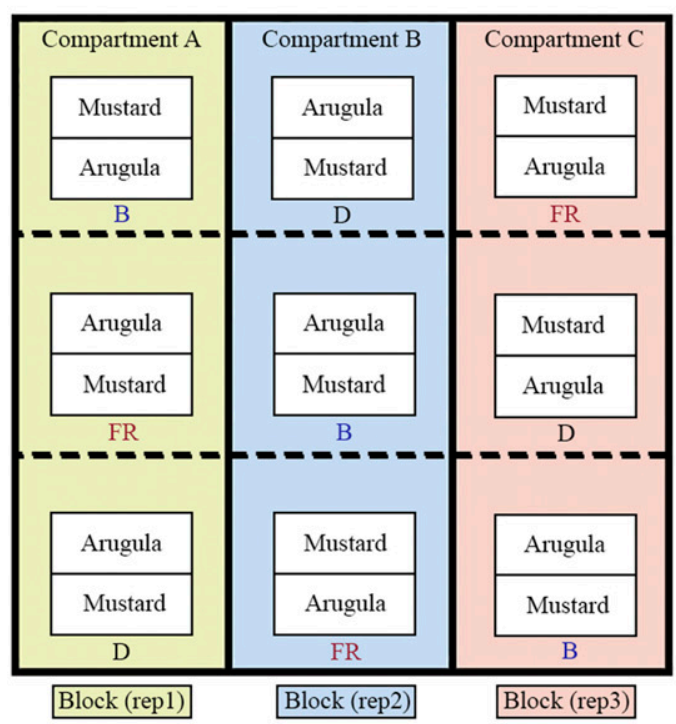

Average DLI: $2.9 \mathrm{~mol} \cdot \mathrm{m}^{-2} \cdot \mathrm{d}^{-1}$

B

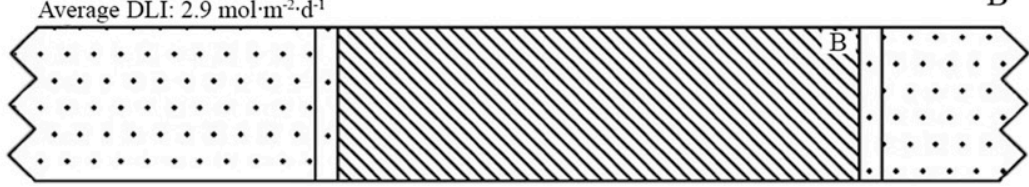

Average DLI: $2.2 \mathrm{~mol} \cdot \mathrm{m}^{-2} \cdot \mathrm{d}^{-1}$

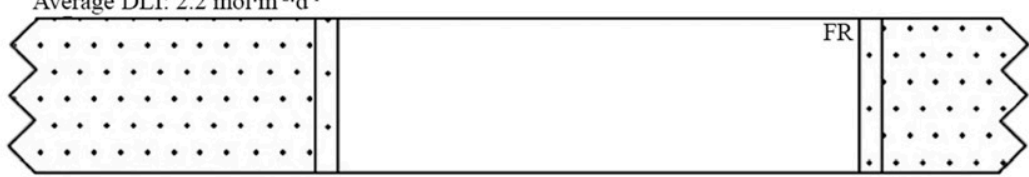

Average DLI: $2.2 \mathrm{~mol} \cdot \mathrm{m}^{-2} \cdot \mathrm{d}^{-1}$

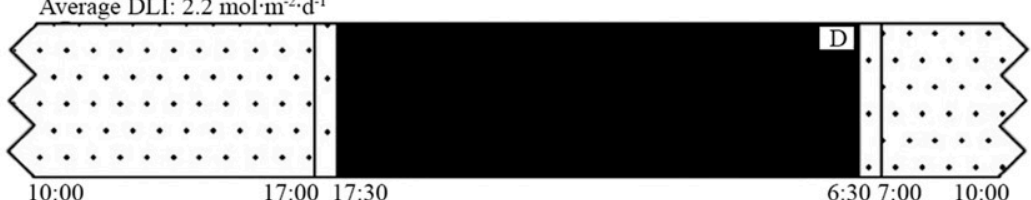

$\because \because \cdot$ Ambient light

No supplemental light
WW Supplemental B light $\left(14 \mu \mathrm{mol} \cdot \mathrm{m}^{-2} \cdot \mathrm{s}^{-1}\right)$ Supplemental FR light $\left(14 \mu \mathrm{mol} \cdot \mathrm{m}^{-2} \cdot \mathrm{s}^{-1}\right)$

Fig. 1. Schematic diagrams of the experimental design and spatial arrangement of the treatments (A) and the time windows of different light treatments during a day $(\mathbf{B}) . \mathrm{B}=$ supplemental blue LED light; $\mathrm{D}=$ no supplemental light; FR = supplemental far-red LED light. 

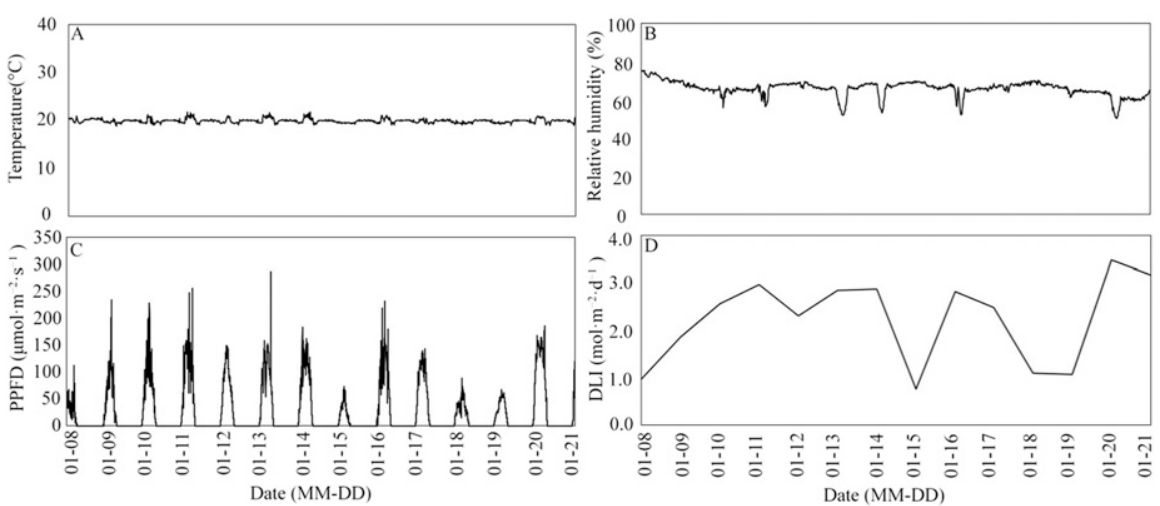

Fig. 2. Daily variations in air temperature (A), relative humidity (B), natural photosynthetic photon flux density (C), and daily light integral (D) in the experimental greenhouse during the lighting treatment period from $1000 \mathrm{HR}$ on 8 Jan. to $1000 \mathrm{HR}$ on 21 Jan. 2019.
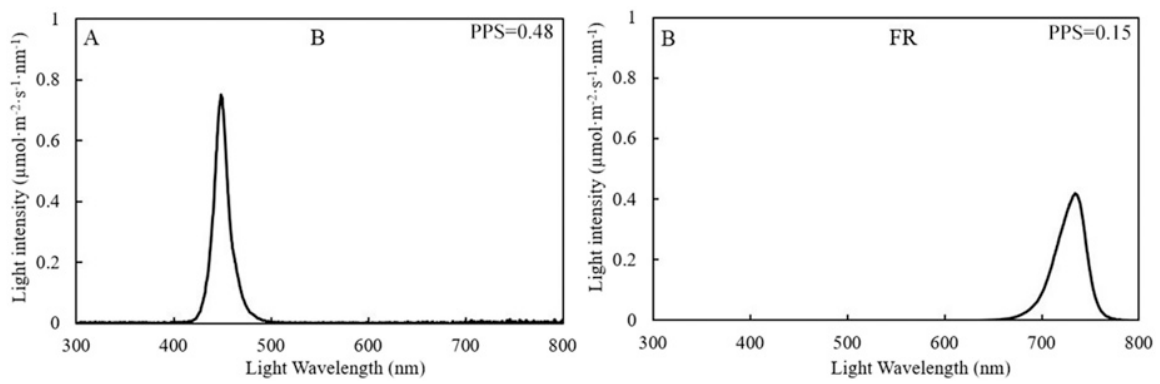

Fig. 3. Spectral distribution and phytochrome photostationary state (PPS) of overnight supplemental blue (B) and far-red (FR) light of $14 \mu \mathrm{mol} \cdot \mathrm{m}^{-2} \cdot \mathrm{s}^{-1}$.

LED array). The lights were on $30 \mathrm{~min}$ after sunset $(\approx 1730 \mathrm{HR})$ until $30 \mathrm{~min}$ before sunrise $(\approx 0630 \mathrm{HR})$ throughout the experimental period (Fig. 1B). Each bench was isolated with automatic blackout when SL was on to avoid neighbor lighting effects. For each bench, light measurements were taken at the canopy level on a $4 \times 4$ square grid (i.e., at 16 different locations) centered below the light within an experimental area of $50 \mathrm{~cm} \times 50 \mathrm{~cm}$ using a radiometrically calibrated spectrometer (XRFlame; Ocean Optics, Dunedin, FL) coupled to a $400-\mathrm{nm} \times 1.9-\mathrm{m}$ patch cord with a CC3 cosine corrector. The measured photon flux density (PFD) values of supplemental B and FR were $13.7 \pm 0.1 \mu \mathrm{mol} \cdot \mathrm{m}^{-2} \cdot \mathrm{s}^{-1}$ and $14.1 \pm$ $0.4 \mu \mathrm{mol} \cdot \mathrm{m}^{-2} \cdot \mathrm{s}^{-1}$ (mean $\pm \mathrm{sE} ; \mathrm{n}=3$ ), respectively.

Growth and appearance quality measurements. Both mustard and arugula microgreens were harvested $14 \mathrm{~d}$ after sowing immediately after the first true leaf started to emerge. In each tray, three subsamples (with a substrate surface area of $76.4 \mathrm{~cm}^{2}$ each, including plants and the substrate) of microgreens were randomly sampled from each tray using a cylindrical core sampler, and all plants within each core were cut from the substrate level and weighed to determine the FW. Then, the harvested plants were placed in paper bags and dried at $65^{\circ} \mathrm{C}$ until a constant weight was reached for DW determination. Another 15 plants were randomly sampled for measurements of plant heights with a ruler. The plant height was measured from the base of the stem to the top of the cotyledon in the life position. From the remainder of the plants left in each tray, three subsets of five plants were sampled randomly for measurements of stem length and diameter, cotyledon area and color, and leaf mass unit area (LMA). The cotyledons were cut from the stems, and the cotyledons and stems were imaged together with a standard reference using a scanner (Canoscan LiDE 25; Canon Inc., Tokyo, Japan) at $600 \mathrm{dpi}$. The averaged cotyledon area, stem length, and diameter of each subset (five plants) were measured by Image J (version 1.42; National Institutes of Health, Bethesda, MD). The stem diameter was measure at $1 \mathrm{~cm}$ above the bottom of the stem. The R, G, and B values of the cotyledon color were also obtained by ImageJ; then, the hue angle of cotyledon was calculated based on method of Karcher and Richardson (2003) after calibration between the scanned and actual color using Munsell color chips (Munsell color system, 2018). After scanning, the cotyledons and stems of five plants were weighed separately and also placed in paper bags and dried at $65^{\circ} \mathrm{C}$ until they reached a constant weight for DW measurements. The LMA was calculated according to Eq. [1].

$$
\begin{aligned}
& \operatorname{LMA}\left(\mathrm{g} \cdot \mathrm{m}^{-2}\right) \\
& \quad=\text { Cotyledon DW / Cotyledon area }
\end{aligned}
$$

Phytochemical measurements. Three subsamples ( $\approx 5 \mathrm{~g} \mathrm{FW}$ each) of fresh plant tissue, including cotyledons, stems, and first true leaves, were randomly taken from each tray, quickly frozen in liquid $\mathrm{N}_{2}$, pulverized into fine powder with an ice-cold mortar and pestle, and collected in a $50-\mathrm{mL}$ conical tube. These flash-frozen microgreen tissues were stored at $-80{ }^{\circ} \mathrm{C}$ before the measurements. Unless otherwise mentioned, all chemicals were purchased from Sigma-Aldrich Inc. (Oakville, ON, Canada).

To measure the total chlorophyll and carotenoid contents, $\approx 20 \mathrm{mg}$ of each frozen sample was used. The samples were resuspended with $1 \mathrm{~mL}$ ice-cold $100 \%$ methanol in $1.7 \mathrm{~mL}$ pre-chilled Eppendorf tubes. The samples were stored on ice under darkness after they were vortexed for $1 \mathrm{~min}$ twice; then, they were centrifuged at $13,000 g_{\mathrm{n}}$ for 5 min at $4{ }^{\circ} \mathrm{C}$. The supernatants were collected in new 1.7-mL pre-cooled Eppendorf tubes and serial dilutions (up to three times) in a final volume of $200 \mu \mathrm{L}$ and prepared in $100 \%$ ice cold methanol. The methanolic extracts were transferred to a 96-well microplate reader (BioTek, Winooski, VT) to measure absorbance. The absorbance readings were obtained at wavelengths of $665 \mathrm{~nm}$, $652 \mathrm{~nm}$, and $476 \mathrm{~nm}$ for chlorophyll $a$, chlorophyll $b$, and carotenoid, respectively. The total chlorophyll and total carotenoid concentrations were calculated using the equations of Lichtenthaler and Buschmann (2001). Each subsample was measured six times (i.e., supernatant twice and its 1:2 and $1: 3$ dilutions twice)

The total phenolic content was measured according to the methods of Ainsworth and Gillespie (2007) with some modifications. Approximately $20 \mathrm{mg}$ of frozen microgreen tissues were transferred in a $1.7-\mathrm{mL}$ Eppendorf tube and resuspended with $1 \mathrm{~mL}$ of ice-cold $100 \%$ methanol, and vortexed twice for $1 \mathrm{~min}$. Then, the samples were centrifuged at $13,000 g_{\mathrm{n}}$ for $5 \mathrm{~min}$ at $4{ }^{\circ} \mathrm{C}$. Then, $25 \mu \mathrm{L}$ of each sample supernatant, 1:2 dilution of the supernatants, standards, and blanks were dispensed in different wells in a 96-well microplate reader. Thereafter, $125 \mu \mathrm{L} 10 \%$ Folin-Ciocalteau reagent was added to each well, and the plate was incubated at room temperature for $10 \mathrm{~min}$. Thereafter, $125 \mu \mathrm{L}$ of $7.5 \%(\mathrm{w} / \mathrm{v}) \mathrm{Na}_{2} \mathrm{CO}_{3}$ was added, and the A was measured at 765 $\mathrm{nm}$. The total phenolic concentrations were calculated against the gallic acid standard curve ranging from 0.018 to $0.6 \mathrm{mg} \cdot \mathrm{L}^{-1}$.

Statistical analyses. Data were analyzed by SPSS statistical software (version 25.0; IBM, New York, NY). Treatment effects were determined by a one-way analysis of variance, and mean separations were performed using Tukey's honestly significant difference test at $P \leq 0.05$.

\section{Results}

Appearance quality. B compared to D increased plant height by $16 \%$ and $10 \%$ in mustard and arugula, respectively (Fig. 4A). FR compared to D increased plant height by $7 \%$ in mustard, but there was no effect on arugula. For both mustard and arugula, plants 
grown under $\mathrm{B}$ were $8 \%$ taller than those under FR. Stem length was increased by $12 \%$ and $20 \%$ under B compared to D for mustard and arugula, respectively. However, stem length was not different between FR and D for both species (Fig. 4B). Also, B compared to FR increased stem length for arugula by $14 \%$, but not for mustard.

Compared with D, B increased the cotyledon area of mustard by $22 \%$, but it did not affect the cotyledon area of arugula (Table 1). In contrast, FR reduced the cotyledon area of arugula by $24 \%$ compared with D. For mustard and arugula, B compared to FR increased the cotyledon area by $44 \%$ and $32 \%$, respectively. There was no difference in LMA among the three treatments $(\mathrm{B}, \mathrm{FR}$, and $\mathrm{D}$ for mustard (Table 1). However, for arugula, B increased LMA by $21 \%$ and $18 \%$ compared with D and FR, respectively, and there was no difference between D and FR. Regarding the stem diameter, stems were thicker under B and D than under FR for both species, although no difference was observed in stem diameter under B and $\mathrm{D}$ for both species. The cotyledon hue angle was smaller for mustard and larger for arugula under $\mathrm{B}$ compared with $\mathrm{D}$ and FR; however, there was no difference in the cotyledon hue angle with D and FR (Table 1). Changes in the hue angle under B relative to D and FR indicated that the cotyledon color increased redness and greenness in mustard and arugula, respectively (Fig. 5).

Plant biomass. Compared with D, B increased the FW $\left(\mathrm{kg} \cdot \mathrm{m}^{-2}\right)$ by $36 \%$ and $28 \%$ for mustard and arugula, respectively, whereas FR did not affect the FW of either species (Fig. 6A). Under B, the FW was increased by $55 \%$ and $26 \%$ compared to FR for mustard and arugula, respectively. There was no difference in DW among D, B, and FR for mustard (Fig. 6B). However, the DW of arugula was increased by $36 \%$ under B compared with D and by $56 \%$ under B compared with FR, and it was not changed by FR or D.

Phytochemical contents. For both species, B compared to D did not affect the total chlorophyll content (Fig. 7A). However, FR compared to $\mathrm{D}$ reduced the total chlorophyll content by $30 \%$ and $31 \%$ for mustard and arugula, respectively. Also, B increased this trait by $52 \%$ compared to FR for arugula but showed no difference for mustard.

The total carotenoid content was unaffected by B compared to D for both species, but it was reduced by $23 \%$ under FR compared to D for arugula (Fig. 7B). B compared to FR increased the total carotenoid content by $42 \%$ and 35\% for mustard and arugula, respectively.

For both species, B compared to D did not change the total phenolic content, but FR compared to D reduced this trait by $23 \%$ and $33 \%$ for mustard and arugula, respectively (Fig. 7C). Under B compared to FR, the total phenolic content was 39\% higher for arugula, but it was not different for mustard.

\section{Discussion}

Overnight supplemental B improves appearance quality compared with D,
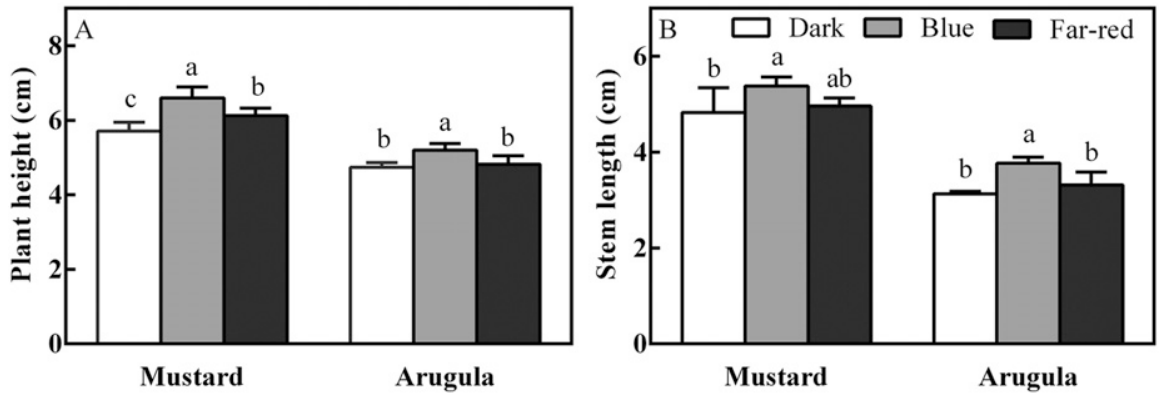

Fig. 4. Plant height $(\mathbf{A})$ and stem length $(\mathbf{B})$ of mustard and arugula microgreens grown in the greenhouse with no supplemental light (D) and $\approx 14 \mu \mathrm{mol} \cdot \mathrm{m}^{-2} \cdot \mathrm{s}^{-1}$ supplemental blue (B) or far-red (FR) light overnight. Data are means \pm SE $(n=3)$. For each species, bars bearing the same letter are not significantly different according to Tukey's honestly significant difference test at $P \leq 0.05$.

Table 1. Cotyledon area, leaf mass per unit area (LMA), stem diameter, and hue angle of mustard and arugula microgreens grown in the greenhouse with no supplemental light [dark (D)] and $\approx 14 \mu \mathrm{mol} \cdot \mathrm{m}^{-2} \cdot \mathrm{s}^{-1}$ supplemental blue (B) or far-red (FR) light overnight.

\begin{tabular}{lcccc}
\hline Treatment & $\begin{array}{c}\text { Cotyledon area } \\
\left(\mathrm{cm}^{2} / \text { plant }\right)\end{array}$ & LMA $\left(\mathrm{g} \cdot \mathrm{m}^{-2}\right)$ & Stem diam $(\mathrm{mm})$ & $\begin{array}{c}\text { Cotyledon hue } \\
\text { angle }\left({ }^{\circ}\right)\end{array}$ \\
\hline D & \multicolumn{3}{c}{ Mustard } \\
B & $1.1 \pm 0.1 \mathrm{~b}^{\mathrm{z}}$ & $76.1 \pm 5.5 \mathrm{a}$ & $0.8 \pm 0.0 \mathrm{a}$ & $44.2 \pm 4.8 \mathrm{a}$ \\
FR & $1.4 \pm 0.1 \mathrm{a}$ & $78.3 \pm 5.9 \mathrm{a}$ & $0.8 \pm 0.0 \mathrm{a}$ & $28.5 \pm 5.2 \mathrm{~b}$ \\
& $0.9 \pm 0.1 \mathrm{~b}$ & $84.3 \pm 14.0 \mathrm{a}$ & $0.7 \pm 0.0 \mathrm{~b}$ & $36.9 \pm 3.5 \mathrm{a}$ \\
$\mathrm{D}$ & \multicolumn{4}{c}{ Arugula } \\
B & $1.6 \pm 0.1 \mathrm{a}$ & $85.7 \pm 3.0 \mathrm{~b}$ & $0.8 \pm 0.0 \mathrm{a}$ & $78.3 \pm 0.5 \mathrm{~b}$ \\
FR & $1.6 \pm 0.1 \mathrm{a}$ & $104.0 \pm 10.2 \mathrm{a}$ & $0.8 \pm 0.0 \mathrm{a}$ & $80.0 \pm 0.1 \mathrm{a}$ \\
& $1.2 \pm 0.1 \mathrm{~b}$ & $81.6 \pm 7.1 \mathrm{~b}$ & $0.7 \pm 0.0 \mathrm{~b}$ & $78.8 \pm 0.5 \mathrm{~b}$ \\
\hline
\end{tabular}

${ }^{\mathrm{z}}$ Data are means $\pm \mathrm{SE}(\mathrm{n}=3)$. For each species, means in the same column followed by the same letter are not significantly different by Tukey's honestly significant difference test at $P \leq 0.05$.

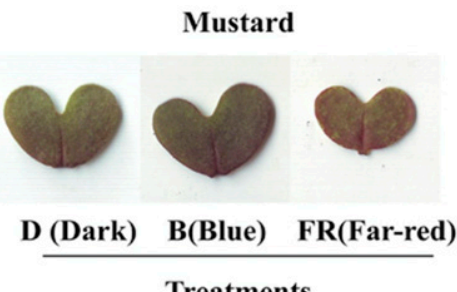

Treatments

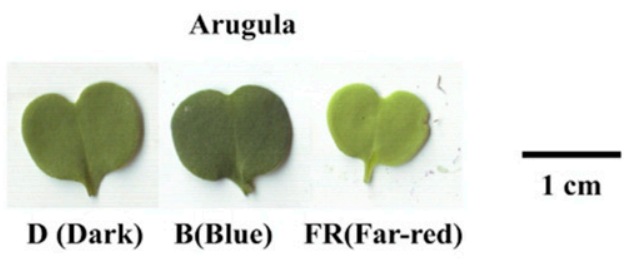

Treatments

Fig. 5. Cotyledons of mustard (left) and arugula (right) microgreens grown in the greenhouse with no supplemental light (D), $\approx 14 \mu \mathrm{mol} \cdot \mathrm{m}^{-2} \cdot \mathrm{s}^{-1}$ supplemental blue (B) or far-red (FR) light overnight.
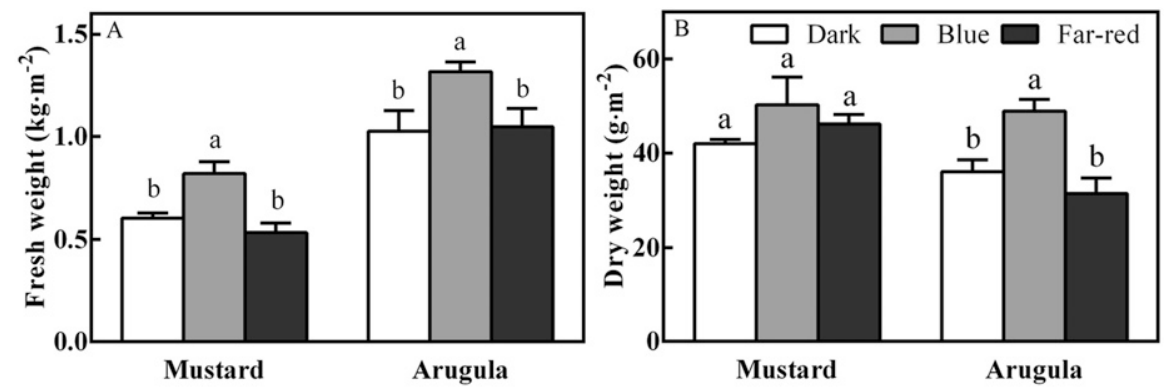

Fig. 6. Fresh (A) and dry (B) weights of mustard and arugula microgreens grown in the greenhouse with no supplemental light (D) and $\approx 14 \mu \mathrm{mol} \cdot \mathrm{m}^{-2} \cdot \mathrm{s}^{-1}$ supplemental blue (B) or far-red (FR) light overnight Data are means $\pm S E(n=3)$. For each species, bars bearing the same letter are not significantly different according to Tukey's honestly significant difference test at $P \leq 0.05$.

showing better effects than supplemental $F R$. For indoor microgreen production using LED lighting as the sole light source, 50 to $100 \mu \mathrm{mol} \cdot \mathrm{m}^{-2} \cdot \mathrm{s}^{-1} \mathrm{~B}$ can promote stem elon- gation to meet the demands of machine harvesting (Kong et al., 2019a). For controlled-environment chrysanthemum production, nighttime supplemental B LED of 20 


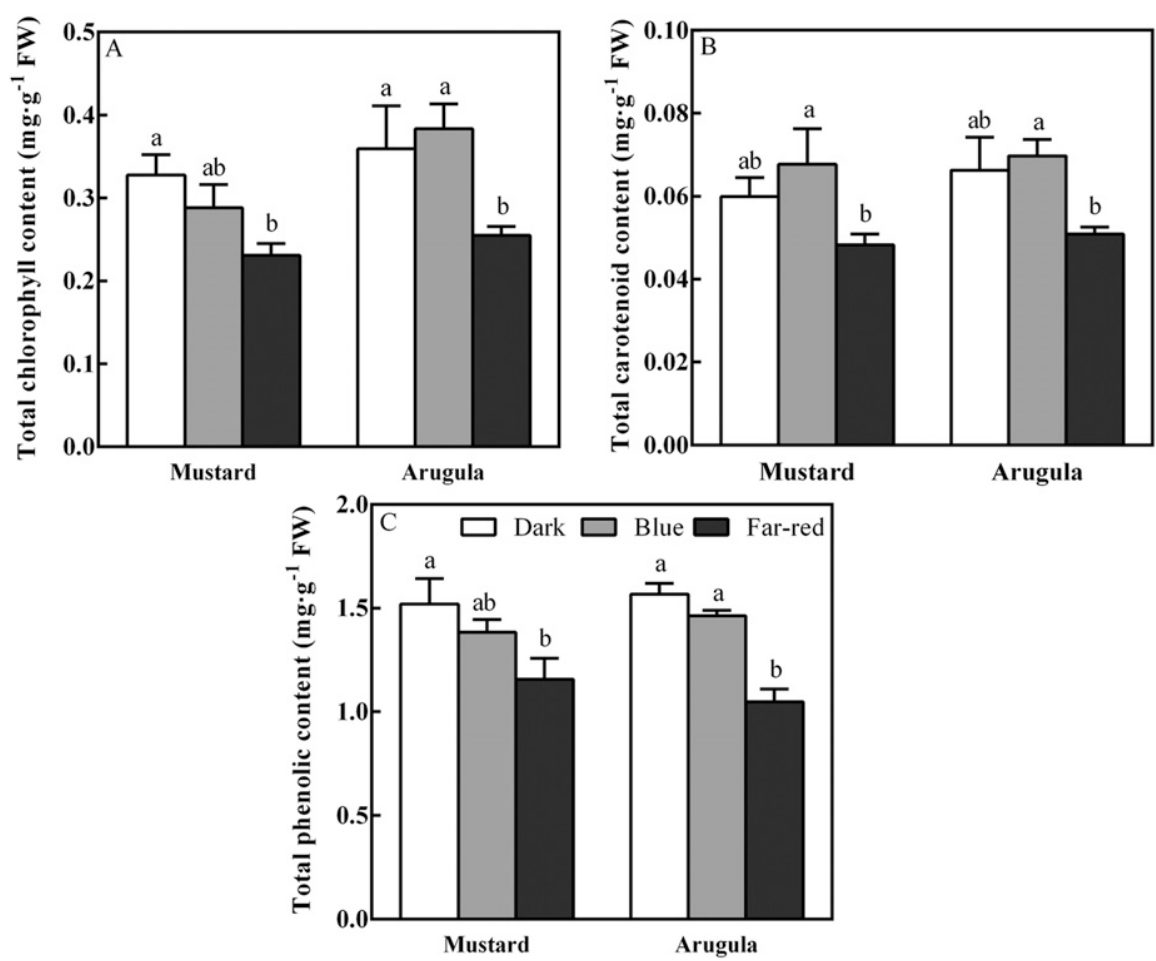

Fig. 7. Total chlorophyll, carotenoid, and phenolic contents of mustard and arugula microgreens grown in the greenhouse with no supplemental light (D) and $\approx 14 \mu \mathrm{mol} \cdot \mathrm{m}^{-2} \cdot \mathrm{s}^{-1}$ supplemental blue (B) or far-red $(F R)$ light overnight. Data are means \pm SE $(n=3)$. For each species, bars bearing the same letter are not significantly different according to Tukey's honestly significant difference test at $P \leq 0.05$.

or $100 \mu \mathrm{mol} \cdot \mathrm{m}^{-2} \cdot \mathrm{s}^{-1}$ promoted stem length (Jeong et al., 2014; Nissim-Levi et al., 2019). Similarly, in the present study, for winter greenhouse microgreen production, overnight supplemental $14 \mu \mathrm{mol} \cdot \mathrm{m}^{-2} \cdot \mathrm{s}^{-1} \mathrm{~B}$ LED, compared with $\mathrm{D}$, increased plant height to taller than that required for machine harvesting (i.e., $5 \mathrm{~cm}$ ) in both species, which was associated with the promoted stem elongation. Obviously, B LED can be used as either sole-source or supplemental light to promote microgreen elongation, thus facilitating machine harvesting. Although the detailed pathway involved in B-induced stem elongation is still unclear, recent studies indicate that deactivated cryptochrome and activated phototropin (i.e., two blue light photoreceptors) in addition to low-activity phytochrome may also contribute to this process (HuchéThélier et al., 2016; Kong et al., 2018b; Kong and Zheng, 2020; Pashkovskiy et al., 2016). Interestingly, in the present study, overnight supplemental FR, compared to D, did not promote stem elongation for both species and increased plant height only for mustard, possibly due to the promoted petiole elongation. It appears that overnight supplemental B compared to FR has a greater promotion effect on microgreen elongation, which is also supported by the increased plant height for both species.

The results from the present study are somehow in contrast to another one of our microgreen studies performed in a growth chamber using an LED combination of $\mathrm{R}$ and $\mathrm{B}(20 \% \mathrm{R}$ and $80 \% \mathrm{~B})$ as the daytime light source (Ying et al., 2020); in that study, nighttime FR compared to $\mathrm{B}$ has a greater promotion effect on elongation. The difference between the two studies might have resulted from the different phytochrome activities before starting supplemental B or FR. In the growth chamber, a combination of $\mathrm{R}$ and B LEDs used for daytime lighting had a higher PPS value (i.e., $\approx 0.88$ ) and, consequently, was supposed to induce high phytochrome activity that could be maintained for several hours even when the light was off (Gaba and Black, 1979). In the greenhouse, the natural light at the end of day normally causes low phytochrome equilibrium due to a low R:FR ratio (Smith, 1982) (e.g., R:FR = 0.6 , and PPS $=0.48$ in our experimental greenhouse, unpublished data). It has been proven that the effect of $\mathrm{B}$ on plant elongation varies with changes in phytochrome equilibrium induced by mixing with other wavelengths (e.g., R/FR) at low levels. High PPS (e.g., >0.6) leads to an inhibition effect of B on plant elongation, whereas low PPS (e.g., $<0.6$ ) leads to a promotion effect of $\mathrm{B}$ on plant elongation (Kong et al., 2019c, 2018b).

Supplemental B, compared with D, also increased the cotyledon area and redness for mustard and the cotyledon thickness (i.e., LMA) and greenness for arugula. The changes in these traits would be more appealing to the customers and could potentially increase the microgreens appearance quality based on our communication with commercial growers. In contrast, supplemental FR reduced the cotyledon area and color and stem diameter for both species compared with $\mathrm{D}$, and it reduced the LMA for arugula and the cotyledon area and stem diameter for both species compared with B. Obviously, supplemental FR also induced some typical responses to shade in other traits (Smith and Whitelam, 1997) despite showing little promotion effects on plant elongation. Pure FR indicates a deep shade signal, which may cause plants to switch to other responses (e.g., decreased leaf greenness through the reduced chlorophyll content) to adapt to the deep shade other than elongation to capture light, in which phytochrome A is known to have a role (Barnes et al., 1996; Gommers et al., 2013; Yang et al., 2018). Considering the negative effects of FR on these plant traits, supplemental B seems to have better effects on the microgreens appearance quality.

Overnight supplemental $B$, rather than $F R$, promotes plant biomass accumulation in microgreens. Compared with $\mathrm{D}$, supplemental B $(\approx 32 \%$ of natural DLI; average, 2.2 $\left.\mathrm{mol} \cdot \mathrm{m}^{-2} \cdot \mathrm{d}^{-1}\right)$ increased the $\mathrm{FW}$ per unit area (i.e., crop yield) for both species, but supplemental FR did not. Also, supplemental B compared to FR increased the crop yield for both species. It appears that overnight supplemental $\mathrm{B}$, rather than $\mathrm{FR}$, can promote fresh biomass accumulation in microgreens during winter greenhouse production. Similar promotion effects have been found by other growth chamber studies. Under daytime fluorescent light of $3.6 \mathrm{~mol} \cdot \mathrm{m}^{-2} \cdot \mathrm{d}^{-1}$, overnight supplemental B of $50 \mu \mathrm{mol} \cdot \mathrm{m}^{-2} \cdot \mathrm{s}^{-1}$ for $14 \mathrm{~h}$ increases the shoot FW by $26 \%$ to $54 \%$ in chrysanthemum, mustard, and onion (Allium сера) compared with no SL, whereas supplemental FR does not affect or reduces the FW (Sase et al., 2012). In the growth chamber under $\mathrm{R}$ and $\mathrm{B}$ LED light of $17.3 \mathrm{~mol} \cdot \mathrm{m}^{-2} \cdot \mathrm{d}^{-1}$, supplemental B of $20 \mu \mathrm{mol} \cdot \mathrm{m}^{-2} \cdot \mathrm{s}^{-1}$ increased the FW of arugula but not of mustard microgreens (Ying et al., 2020). These studies show the potential of using supplemental B to increase $\mathrm{FW}$, although the efficiency of the promotion is affected by daytime light conditions, supplemental light intensity, and plant species. The higher yield of microgreens under supplemental $\mathrm{B}$, in the present study, was also supported by the modified appearance quality traits such as longer and thicker stems or larger and thicker cotyledons. The increased yield under overnight supplemental B will potentially benefit microgreen production becausee these crops are sold on a FW basis.

In addition to $\mathrm{FW}$, compared with $\mathrm{D}$, supplemental B increased DW per unit growing area for arugula, but supplemental FR did not for either species. Also, supplemental B compared to FR increased DW for arugula. It appears that overnight supplemental B, rather than FR, can promote dry biomass accumulation in some microgreen species (i.e., arugula). The increased DW under supplemental $\mathrm{B}$, rather than FR in the present study might have resulted from the SL-increased photoassimilate accumulation because B falls in the range of $P A R$, but FR does not. However, the contribution of photosynthetic assimilates to microgreen biomass may vary among species with different seed sizes. During the short growth period of microgreens, plants 
mainly experience a transition from heterotrophic to autotrophic growth, and photosynthesis contributes less to plant biomass than seed reservation for larger compared to smaller species (Jones-Baumgardt et al., 2019, 2020). In the present study, mustard had a larger seed size than arugula (1.63 vs. $1.56 \mathrm{mg} / \mathrm{seed}$ ), which may partly explain why supplemental B, compared with D or supplemental FR, did not increase DW in mustard but did in arugula.

Overnight supplemental $B$ does not reduce phytochemical contents compared with D, but supplemental FR does. It has been documented that higher $B$ levels can increase phytochemical contents in plants. For example, when up to $50 \% \mathrm{~B}$ is added to $\mathrm{R}$, the chlorophyll content increases in cucumber seedlings (Hogewoning et al., 2010). The total carotenoid content increases in beet (Beta vulgaris L.) microgreens when 0\% up to $47 \% \mathrm{~B}$ is added to $\mathrm{R}$ (Samuoliene et al., 2017). The total phenolic concentration in lettuce increases when adding $0 \%$ up to $47 \%$ $\mathrm{B}$ to $\mathrm{R}$ (Son and Oh, 2013). However, in the present study, supplemental B did not affect the total chlorophyll, carotenoid, or phenolic contents (mg.g ${ }^{-1}$ FW) in either species compared with D. Possibly, in the previous studies, B acted together with the other wavelength (e.g., R); however, in the present study, B was applied alone during the nighttime and at very low levels. It has been proven that B mediates phytochemical (e.g., anthocyanin) synthesis mainly through cryptochrome, which requires active phytochrome for full expression, and this requirement can be supplied by low levels of R (Ahmad and Cashmore, 1997). Another explanation for the inconsistency between the previous studies and ours is that the responses to B might vary among species or even cultivars. A previous greenhouse study of pak choi (Brassica oleracea) indicated that daytime supplemental $50 \mu \mathrm{mol} \cdot \mathrm{m}^{-2} \cdot \mathrm{s}^{-1}$ of B, compared with no SL, does not increase the total chlorophyll, carotenoid, or phenolic contents in green-leafed cultivars, but it does increase those phytochemical contents in redleafed cultivars (Zheng et al., 2018).

In the present study, supplemental FR reduced the contents of phytochemicals (i.e., total chlorophyll, carotenoid, and phenolic contents) in microgreens compared with D or supplemental B in most cases. Similarly, lower chlorophyll content (either unit leaf area or unit FW) was found in petunia (Petunia axilaris) plants treated with FR compared with $\mathrm{R}$ at the end of the photoperiod (Casal et al., 1987). Supplementing FR to cool white fluorescent light causes plants to express diverse shade-avoidance syndrome, such as decreasing the contents of chlorophyll and carotenoid, which corresponds with decreasing phytochrome equilibrium (Kalaitzoglou et al., 2019). The biosynthesis of chlorophyll is negatively regulated by phytochrome interacting factor 1 (PIF 1), and its activity is greatly affected by phytochrome equilibrium (Huq et al., 2004). Also, FR radiation, as a light competition signal, can elicit down-regulation of plant chemical defenses (e.g., reduced biosynthesis of phenolic) (Moreno et al., 2009). This may partly explain the decrease in the total phenolic content under supplemental FR in the present study.

In summary, during winter greenhouse production (with a natural DLI of $\approx 2.2$ $\mathrm{mol} \cdot \mathrm{m}^{-2} \cdot \mathrm{d}^{-1}$ at the canopy level), overnight supplemental $14 \mu \mathrm{mol} \cdot \mathrm{m}^{-2} \cdot \mathrm{s}^{-1} \mathrm{~B}$, compared with $\mathrm{D}$ or $\mathrm{FR}$, improved the microgreen appearance quality demonstrated by the increased plant height (essential for machine harvesting), stem length, cotyledon area, LMA, or cotyledon coloring, which varied with the species. Also, B compared to D, increased the microgreen yield, but FR compared to D did not. Furthermore, FR compared to $\mathrm{D}$ or $\mathrm{B}$ reduced the contents of phytochemicals (i.e., total chlorophyll, carotenoid, and phenolic contents). Therefore, overnight supplemental low-intensity B, rather than FR, is beneficial to winter greenhouse production of microgreens.

\section{Literature Cited}

Ahmad, M. and A.R. Cashmore. 1997. The bluelight receptor cryptochrome 1 shows functional dependence on phytochrome A or phytochrome B in Arabidopsis thaliana. Plant J. 11:421-427.

Ainsworth, E.A. and K.M. Gillespie. 2007. Estimation of total phenolic content and other oxidation substrates in plant tissues using Folin-Ciocalteu reagent. Nat. Protoc. 2:875877.

Barnes, S.A., N.K. Nishizawa, R.B. Quaggio, G.C. Whitelam, and N.H. Chua. 1996. Far-red light blocks greening of arabidopsis seedlings via a phytochrome A-mediated change in plastid development. Plant Cell 8:601-615.

Brandon, M.F., N. Lu, T. Yamaguchi, M. Takagaki, T. Maruo, T. Kozai, and W. Yamori. 2012. Next evolution of agriculture: A review of innovations in plant factories, p. 723-740. In: M. Pessarakli (eds.) Handbook of Photosynthesis. CRC Press, Boca Raton, FL.

Casal, J.J., P.J. Aphalo, and R.A. Sanchez. 1987. Phytochrome effects on leaf growth and chlorophyll content in Petunia axilaris. Plant Cell Environ. 10:509-514.

Chia, P.L. and C. Kubota. 2010. End-of-day far-red light quality and dose requirements for tomato rootstock hypocotyl elongation. HortScience 45:1501-1506.

Critten, D.L. 1993. A review of the light transmission into greenhouse crops. Acta Hort. 328:9-32.

Demers, D.A. and A. Gosselin. 2002. Growing greenhouse tomato and sweet pepper under supplemental lighting: Optimal photoperiod, negative effects of long photoperiod and their causes. Acta Hort. 580:83-88.

Demotes-Mainard, S., T. Péron, A. Corot, J. Bertheloot, J. Le Gourrierec, S. Pelleschi-Travier, L. Crespel, P. Morel, L. Huché-Thélier, R. Boumaza, A. Vian, V. Guérin, N. Leduc, and S. Sakr. 2016. Plant responses to red and far-red lights, applications in horticulture. Environ. Exp. Bot. 121:4-21.

Faust, J.E. and J. Logan. 2018. Daily light integral: A research review and high-resolution maps of the United States. HortScience 53:1250-1257.

Gaba, V. and M. Black. 1979. Two separate photoreceptors control hypocotyl growth in green seedlings. Nature 278:51-54.
Gómez, C., R.C. Morrow, C.M. Bourget, G.D. Massa, and C.A. Mitchell. 2013. Comparison of intracanopy light-emitting diode towers and overhead high-pressure sodium lamps for supplemental lighting of greenhouse-grown tomatoes. HortTechnology 23:93-98.

Gommers, C.M.M., E.J.W. Visser, K.R.S. Onge, L.A.C.J. Voesenek, and R. Pierik. 2013. Shade tolerance: When growing tall is not an option. Trends Plant Sci. 18:65-71.

Hofstra, G., G.J.A. Ryle, and R. Williams. 1969. Effects of extending the day length with lowintensity light on the growth of wheat and cocksfoot. Aust. J. Biol. Sci. 22:333-341.

Hogewoning, S.W., G. Trouwborst, H. Maljaars, H. Poorter, W. van Ieperen, and J. Harbinson. 2010. Blue light dose-responses of leaf photosynthesis, morphology, and chemical composition of Cucumis sativus grown under different combinations of red and blue light. J. Expt. Bot. 61:3107-3117.

Huché-Thélier, L., L. Crespel, J.L. Gourrierec, P. Morel, S. Sakr, and N. Leduc. 2016. Light signaling and plant responses to blue and UV radiations-Perspectives for applications in horticulture. Environ. Exp. Bot. 121:22-3809.

Huq, E., B. Al-Sady, M. Hudson, C. Kim, K. Apel, and P.H. Quail. 2004. Phytochrome-interacting factor 1 is a critical bHLH regulator of chlorophyll biosynthesis. Biol. Sci. Collect. 305: 1937-1941.

Islam, M.A., D. Tarkowská, J.L. Clarke, D.R. Blystad, H.R. Gislerød, S. Torre, and J.E. Olsen. 2014. Impact of end-of-day red and far-red light on plant morphology and hormone physiology of poinsettia. Sci. Hort. 174:77-86.

Ito, A., T. Saito, T. Nishijima, and T. Moriguchi 2014. Effect of extending the photoperiod with low-intensity red or far-red light on the timing of shoot elongation and flower-bud formation of 1-year-old Japanese pear (Pyrus pyrifolia). Tree Physiol. 34:534-546.

Jeong, S.W., S.W. Hogewoning, and W. van Ieperen. 2014. Responses of supplemental blue light on flowering and stem extension growth of cut chrysanthemum. Scientia Hort. 165:69-74.

Jones-Baumgardt, C., D. Llewellyn, Q. Ying, and Y. Zheng. 2019. Intensity of sole-source lightemitting diodes affects growth, yield, and quality of Brassicaceae microgreens. HortScience 54:1168-1174.

Jones-Baumgardt, C., D. Llewellyn, and Y. Zheng. 2020. Different microgreen genotypes have unique growth and yield responses to intensity of supplemental PAR from light-emitting diodes during winter greenhouse production in southern Ontario. HortScience 55:156-163.

Kalaitzoglou, P., W. Van Ieperen, J. Harbinson, M. Van Der Meer, S. Martinakos, K. Weerheim C.C.S. Nicole and L.F.M. Marcelis. 2019. Effects of continuous or end-of-day far-red light on tomato plant growth, morphology, light absorption, and fruit production. Front. Plant Sci. 10:1-11.

Karcher, D.E. and M.D. Richardson. 2003. Quantifying turfgrass color using digital image analysis. Crop Sci. 43:943-951.

Kong, Y., D. Kamath, and Y. Zheng. 2019a. Blue versus red light can promote elongation growth independent of photoperiod: A study in four Brassica microgreens species. HortScience 54:1955-1961.

Kong, Y., K. Schiestel, and Y. Zheng. 2019b. Pure blue light effects on growth and morphology are slightly changed by adding low-level UVA or far-red light: A comparison with red light in four microgreen species. Environ. Exp. Bot. 157:58-68. 
Kong, Y., K. Schiestel, and Y. Zheng. 2019c. Maximum elongation growth promoted as a shadeavoidance response by blue light is related to deactivated phytochrome: A comparison with red light in four microgreen species. Can. J. Plant Sci.

Kong, Y., D. Llewellyn, and Y. Zheng. 2018a. Response of growth, yield, and quality of pea shoots to supplemental light-emitting diode lighting during winter greenhouse production. Can. J. Plant Sci. 740:732-740.

Kong, Y., M. Stasiak, M.A. Dixon, and Y. Zheng. 2018b. Blue light associated with low phytochrome activity can promote elongation growth as shade-avoidance response: A comparison with red light in four bedding plant species. Environ. Exp. Bot. 155:345-359.

Kong, Y. and Y. Zheng. 2019. Response of growth, yield, and quality of edible-podded snow peas to supplemental LED lighting during winter greenhouse production. Can. J. Plant Sci. 99:676-687.

Kong, Y. and Y. Zheng. 2020. Phototropin is partly involved in blue-light-mediated stem elongation, flower initiation, and leaf expansion: A comparison of phenotypic responses between wild Arabidopsis and its phototropin mutants. Environ. Exp. Bot. 171: 103967.

Kyriacou, M.C., Y. Rouphael, F. Di, A. Kyratzis, F. Serio, M. Renna, S. De Pascale, and P. Santamaria. 2016. Micro-scale vegetable production and the rise of microgreens. Trends Food Sci. Technol. 57:103-115.

Lichtenthaler, H.K. and C. Buschmann. 2001. Chorophylls and carotenoids: Measurement and characterization by UV-VIS spectroscopy. Food Anal. Chemistry F4.3.1-F4.3.8.

Llewellyn, D., Y. Zheng, and M. Dixon. 2013. Survey of how hanging baskets influence the light environment at lower crop level in ornamental greenhouses in Ontario, Canada. HortTechnology 23:823-829.
Lund, J.B., T.J. Blom, and J.M. Aaslyng. 2007. End-of-day lighting with different red/farred ratios using light-emitting diodes affects plant growth of Chrysanthemum $x$ morifolium Ramat. 'Coral Charm'. HortScience 42:16091611.

Mah, J.J., D. Llewellyn, and Y. Zheng. 2019. Protocol for converting spectrometer radiometric data to photon flux units. Guelph, University of Guelph. <http://www.ces.uoguelph.ca/ TechNotes.shtml $>$.

Mir, S.A., M.A. Shah, and M.M. Mir. 2017. Microgreens: Production, shelf life, and bioactive components. Crit. Rev. Food Sci. Nutr. 57:2730 2736.

Moreno, J.E., Y. Tao, J. Chory, and C.L. Ballare. 2009. Ecological modulation of plant defense via phytochrome control of jasmonate sensitivity. Proc. Natl. Acad. Sci. 106:1-6.

Nissim-Levi, A., M. Kitron, Y. Nishri, R. Ovadia, I. Forer, and M. Oren-Shamir. 2019. Effects of blue and red LED lights on growth and flowering of Chrysanthemum morifolium. Scientia Hort. 254:77-83.

Pashkovskiy, P.P., A.V. Kartashov, I.E. Zlobin, S.I. Pogosyan, and V.V. Kuznetsov. 2016. Blue light alters miR167 expression and microRNAtargeted auxin response factor genes in Arabidopsis thaliana plants. Plant Physiol. Biochem. 104:146-154.

Samuoliene, G., A.S. Akvile Viršile, A. Brazaityte, J. Jankauskienè, S. Sakalauskienè, V. Vaštakaitè, A. Novičkovas, A. Viškelienè, and P. Duchovskis. 2017. Blue light dosage affects carotenoids and tocopherols in microgreens. Food Chem. 228:50-56.

Sager, J.C., W.O. Smith, J.L. Edwards, and K.L. Cyr. 1988. Photosynthetic efficiency and phytochrome photoequilibria determination using spectral data. Trans. ASAE 31:1882-1889.

Sase, S., C. Mito, and L. Okushima. 2012. Effect of overnight supplemental lighting with different spectral LEDs on the growth of some leafy vegetables. Acta Hort. 956:327-334.

Son, K.H. and M.M. Oh. 2013. Leaf shape, growth, and antioxidant phenolic compounds of two lettuce cultivars grown under various combinations of blue and red light-emitting diodes. HortScience 48:988-995.

Smith, H. 1982. Light quality, photoperception, and plant strategy. Annu. Rev. Plant Physiol. 33:481-518.

Smith, H. and G.C. Whitelam. 1997. The shade avoidance syndrome: Multiple responses mediated by multiple phytochromes. Plant Cell Environ. 20:840-844.

Treadwell, D.D., R. Hochmuth, L. Landrum, and W. Laughlin. 2016. Microgreens: A new specialty crop. Univ. Florida IFAS Ext. Bul. HS1164. <https://edis.ifas.ufl.edu/hs1164>

Xiao, Z., G.E. Lester, Y. Luo, and Q. Wang. 2012. Assessment of vitamin and carotenoid concentrations of emerging food products: Edible microgreens. J. Agr. Food Chem. 60:76447651.

Yang, C., F. Xie, Y. Jiang, Z. Li, X. Huang, and L. Li. 2018. Phytochrome A negatively regulates the shade avoidance response by increasing auxin/indole acidic acid protein stability. Dev. Cell 44:29-41.e4.

Ying, Q., Y. Kong, and Y. Zheng. 2020. Applying blue light alone, or in combination with far-red light, during nighttime increases elongation without compromising yield and quality of indoor-grown microgreens. HortScience 55: 876-881.

Zheng, Y., Y. Zhang, H. Liu, Y. Li, Y. Liu, Y. Hao, and B. Lei. 2018. Supplemental blue light increases growth and quality of greenhouse pak choi depending on cultivar and supplemental light intensity. J. Integr. Agr. 17:22452256 . 